\title{
The Race Between Demand and Supply: Tinbergen's Pioneering Studies of Earnings Inequality
}

\author{
James J. Heckman ${ }^{1}$ \\ Published online: 24 May 2019 \\ (c) The Author(s) 2019
}

\begin{abstract}
Understanding inequality and devising policies to alleviate it was a central focus of Jan Tinbergen's lifetime research. He was far ahead of his time in many aspects of his work. This essay places his work in the perspective of research on inequality in his time and now, focusing on his studies on the pricing of skills and the evolution of skill prices. In his most fundamental contribution, Tinbergen developed the modern framework for hedonic models as part of his agenda for integrating demand and supply for skills to study determination of earnings and its distribution and the design of effective policy. His lifetime emphasis on social planning caused some economists to ignore his fundamental work.
\end{abstract}

Keywords Income inequality $\cdot$ Hedonic models $\cdot$ General equilibrium $\cdot$ Models of inequality

JEL Classification B31 $\cdot$ D31 $\cdot$ D33 $\cdot$ D63 $\cdot$ I24 $\cdot$ J20 $\cdot$ P21

\section{Introduction}

Jan Tinbergen was-and remains - a towering figure in economics. Educated as a physicist, he applied his training in rigorous empirical science to study the economy. He developed and applied formal economic theories to explain and interpret a variety of economic data. He tested his theories against competing models. He

\footnotetext{
This research was supported in part by the American Bar Foundation and by NIH Grants NICHD R37HD065072 and NICHD R01HD054702. The views expressed in this paper are solely those of the authors and do not necessarily represent those of the funders or the official views of the National Institutes of Health.
}

James J. Heckman

jjh@uchicago.edu

1 Center for the Economics of Human Development, University of Chicago, 1126 East 59th

Street, Chicago, IL 60637, USA 
used evidence-based science to design effective economic policies. Underlying his research was an abiding interest in trying to make the world a better place.

The Great Depression spurred his interest in aggregate business cycle theory. ${ }^{1}$ This led him to conduct his pioneering work on macro models of the economy which is well-known and widely respected. He sought to understand the aggregate forces that shape earnings and income. His work on economic planning was an adjunct of this research. Throughout his career, he insisted that effective policy was possible and the design of policy required a deep understanding of the mechanisms that produced economic outcomes. In modern jargon, Tinbergen went beyond "treatment effects" to investigate models that explain the mechanisms generating treatment effects and how they might be used to design effective policies.

Tinbergen also examined the micro determinants of inequality. In doing so, he pioneered the study of the equilibrium effects of demand and supply of vectors of attributes in determining earnings inequality.

His research emphasized the multiplicity of the attributes that determine labor income. He focused mainly on education as a determinant of earnings because he viewed it as a primary and useful policy lever. However, he also considered the role of both cognitive and noncognitive abilities as determinants of earnings, although he largely regarded them as God-given traits that were suitable targets for lumpsum taxation. He partially retreated from this stance when he revisited his earlier studies. $^{2}$

His work went far beyond the approach of his day that assumed earnings were determined as the payments to individual productive components with prices determined by unspecified background market forces (e.g., Staehle 1943; and the formal statement of this approach in Welch 1969). He developed equilibrium models of demand and supply showing how vectors of continuous attributes are priced. In doing so, he developed the microfoundations of hedonic pricing. In previous research, Court (1939) developed the first empirical hedonic model and priced automobiles in terms of their attributes. Court (1941) developed a model of the demand for a continuum of qualities but did not develop the supply side of his model and hence, the equilibrium determination of prices. Tinbergen's pioneering research on the economics of quality and variety (hedonics) was an important conceptual breakthrough that is not adequately recognized.

Tinbergen (1975) synthesized his ideas up to that date and used his analytical framework to unify two then disparate literatures: (a) the demand-oriented educational planning literature (Bowles 1970; Dougherty 1972; Dresch 1975; Fallon and Layard 1975); and (b) the supply-oriented human capital literature (Becker 1964; Mincer 1974). ${ }^{3}$ Uniting these literatures, he developed and estimated tractable economic models of the market equilibrium pricing of education and other skills and a framework for discussing the roles of technology and supply-side policies in determining the prices of skills with associated nonlinear pricing schedules. His

\footnotetext{
1 See Kol and Wolff (1993).

2 Tinbergen (1977).

${ }^{3}$ For a contemporary assessment of the 1975 book, see Haveman (1977).
} 
framework is at the core of later work by Katz and Murphy (1992), Goldin and Katz (2009), and Acemoglu and Autor (2011), among others. He moved well beyond standard efficiency unit models to consider a continuum of skills. His research anticipates the work of Rosen (1974) on hedonic models by two decades.

He went well beyond the then nascent human capital literature that used an amorphous notion of "human capital" that was sometimes equated with cognitive ability (see, e.g., Spence 1974). He considered vectors of attributes that determine market productivity, including education, work experience, ability, personality traits, and the like. His work provided, and continues to provide, a framework for the study of the sorting of heterogenous workers and firms (see, e.g., Beaudry et al. 2016; Lamadon et al. 2017; Lindenlaub 2017; Yamaguchi 2012). He integrated market responses into the technocratic educational planning literature.

This essay is in four parts. In the next part, I place Tinbergen's work in context. Following that, I discuss Tinbergen's approach to using supply and demand to interpret the pricing of skills - a fundamental conceptual achievement. I show how his work is related to the modern literature on hedonics and how it was and still is used to integrate the roles of technical change and supply side policies into a common equilibrium framework. I then discuss Tinbergen's research on educational planning and his work on optimal inequality. In the final section, I assess his contributions and discuss why they are relevant today. I speculate about why his work was neglected by many of his contemporaries.

\section{Tinbergen's Work in Context}

Economists have developed many models of income and earnings inequality. ${ }^{4}$ These models coexist but do not always cohere.

Tinbergen (1956) broke new ground by applying the standard tools of supply and demand for productive attributes to characterize the market equilibrium pricing of skills. In retrospect, this looks like a pedestrian achievement. In its time, his work was so bold and original that it failed to be widely understood and appreciated. It didn't help that his fundamental (1956) paper was published in a relatively obscure German journal, ${ }^{5}$ albeit in English.

In the 1950s, economics was largely caught in the grip of Keynesian economics, which emphasized demand-side macro factors and policies. It tended to overlook the supply side of the economy. There was also widespread skepticism about the value of neoclassical theory for understanding economic phenomena. The push for micro foundations of macroeconomics was decades away. Modern labor economics was in its infancy. Price theory was only starting to be applied to understand the labor market. ${ }^{6}$

\footnotetext{
${ }^{4}$ See, e.g., the essays in Reder (1969), which surveys the older literature. See Atkinson and Bourguignon (2000) for a more recent survey.

${ }^{5}$ Weltwirtschaftliches Archiv.

${ }^{6}$ See Heckman (2014).
} 
Although Tinbergen often questioned the efficiency of markets, he thoroughly understood neoclassical economics. He emphasized that for all, except centrally planned economies, the market sector was an important part of the economy and that understanding the impacts of policies on markets was essential to making successful evaluations of policies. ${ }^{7}$ Far ahead of his peers, he applied price theory in a equilibrium setting to understand the pricing of skills.

In developing and estimating equilibrium models of demand and supply for the continua of productive attributes, he was far ahead of his peers. In the early 1970s, human capital theory was regnant. Becker (1964) and Mincer (1974) were the most influential works of the period. Instead of assuming a homogenous ill-defined substance "human capital," as those authors did, Tinbergen explicitly considered the multiplicity of factors producing earnings and how they are priced.

The human capital theory of the era was vague about the pricing of human capital. It emphasized "rates of return" which were, in certain specifications, prices. ${ }^{8}$ Demand considerations were in the background. He brought the full weight of economics to understand the pricing of heterogenous productive attributes. By examining both demand and supply, he was able to integrate and assess the impact of both demand-side and supply-side policies on inequality in earnings. Thus, he could assess within a common framework the impact of taxation, policies to promote educational attainment and policies to encourage $\mathrm{R}$ and $\mathrm{D}$. By considering the multiplicity of attributes possessed by workers, he emphasized that earnings can be equalized in different ways by changing the composition of the skill bundles that workers brought to the market or by changing the prices of components of these bundles or by some combination of these approaches. He also explicitly accounted for institutional factors, such as trade unions and corporatist bargaining over wages at the national level.

His emphasis on the sorting of heterogenous workers to heterogenous firms was revolutionary in its day. His framework is still used in this context (see, e.g., Lindenlaub 2017; Lindenlaub and Postel-Vinay 2017) because of its tractability and insight. His hedonic model advanced the mechanical educational planning literature by making the skill requirements of jobs endogenous instead of fixed, as is still common in the literature (see Autor and Dorn 2013). In his model, the skills used in a labor market task respond to demand for the final product for which the task is used and the availability of supplies of attributes.

His analysis of the impact of technical change on labor earnings anticipated the later work by Katz and Murphy (1992) and a large literature surveyed in Acemoglu and Autor (2011) but was more general because he also considered supply. He did not, however, develop fully dynamic models of the supply of skills in equilibrium settings. This was done much later in equilibrium settings. ${ }^{9}$

He introduced the notion of a race between the demand for and supply of education with technology as a prime determinant of demand. This notion has been

\footnotetext{
7 See, e.g., Tinbergen (1954) and Tinbergen (1956).

8 See Heckman et al. (2006) and Heckman et al. (2018).

9 See Heckman et al. (1998) and later work by Johnson and Keane (2013).
} 
popularized by Goldin and Katz (2009). He estimated these models on Dutch data and used the fitted models to investigate the impacts of specific tax and technology changes. He introduced an explicit social welfare function which he justified using ethical considerations. He considered what policies produce equal utility among persons and distinguished those from policies that promote aggregate optimality. He considered the tradeoff between equity and social optimality and the information required to implement these policies.

His 1975 book attempted to integrate his models into a general macroeconomic framework, but this analysis is at best sketchy. He briefly discussed Marxist theories, but notes that their emphasis on capital as a source of inequality ignores the central role of skills and the heterogeneity of skills in explaining income inequality in modern economies. This point applies with full force to the recent influential analysis of Piketty. ${ }^{10}$

Tinbergen updated his 1975 analysis in a 1977 paper published in this journal. ${ }^{11}$ He clarified how his models applied to educational planning and revised the empirical estimates reported in his 1975 book. He carefully delineated traits that could be augmented from those that were endowed and could be the basis for optimal taxation schemes. He notes that certain personality traits are produced in schooling. We have come to learn that many more of the personality traits he took as given can, in fact, be enhanced. Modern understanding of skill formation suggests in retrospect, that he should have used a broader notion of supply. ${ }^{12}$

In order to conduct the empirical work in his 1975 book, Tinbergen ignored a key idea of his 1956 paper: that "skill requirements" are not only technologically determined, but respond to market forces as shaped by skill endowments. However, in the 1975 book, he does allow for technological progress to alter skill requirements. He talks about "skill requirements" of jobs (as does a large recent literature) as if they are solely technologically determined. ${ }^{13}$

\section{Tinbergen's Hedonic Model}

The modern hedonic model is one of the crowning achievements of Tinbergen's research on inequality. His contribution to this literature is still not widely appreciated. ${ }^{14}$ For this reason, I devote an entire section to his breakthrough analysis. While Tinbergen focused on the labor market, his model can also be applied to product markets. $^{15}$

\footnotetext{
10 Piketty (2014).

11 Tinbergen (1977).

12 See Heckman (2008) and Heckman and Mosso (2014).

13 See, e.g., Autor and Dorn (2013).

14 This section draws on some of the material in Ekeland et al. (2004).

15 See Rosen (1974).
} 
I first lay out the general hedonic model and then give Tinbergen's explicit model, which is still in wide use because it is so tractable. Consider a general hedonic model for a labor market setting. The model is essentially static, as was Tinbergen's. Workers match to single worker firms. Let $z$ be an attribute vector characterizing jobs. $P(z)$ is the earnings of workers supplying attribute vector $z$, which is a disamenity. Let $R$ be unearned income.

Consider the supply of attributes to the market. Define $U(c, z, x, \varepsilon, A)$ as the preferences of workers where $x$ and $\varepsilon$ represent observed (by the econometrician) and unobserved characteristics of workers that vary across persons, $A$ represents preference parameters common across persons and $c$ is consumption where $c=P(z)+R$. Higher values of $z$ lead to lower values of $U$. For ease of exposition, assume $R=0$. Given $P(z)$, a twice continuously differentiable price function, and assuming the utility function is twice differentiable, ${ }^{16}$ one obtains the following first and second order conditions for a maximum

$$
\begin{gathered}
U_{c}(c, z, x, \varepsilon, A) P_{z}(z)+U_{z}(c, z, x, \varepsilon, A)=0 \\
U_{z z^{\prime}}+U_{c} P_{z z^{\prime}}+2 P_{z} U_{c z^{\prime}}+P_{z} U_{c c}\left(P_{z}\right)^{\prime} \text { is negative definite. }
\end{gathered}
$$

These conditions characterize optimal job attribute choices for each worker. For each location $z$ in attribute space, they characterize the set of workers who choose that location. Workers are heterogenous and differ in their willingness to supply attribute $z$ to the market.

Tinbergen also analyzed the demand side. Firms demand attribute $z$ and maximize profits which are output $\Gamma(z, y, \eta, B)$ minus production costs $P(z)$ where $y$ and $\eta$ are observable and unobservable vectors of technology parameters that vary across firms and $B$ is a common technology parameter shared by all firms. Observables and unobservables are defined with respect to what the econometrician observes. Assume that the production function is twice differentiable. Profits are

$$
\Pi(z, y, \eta, B, P(z))=\Gamma(z, y, \eta, B)-P(z)
$$

and the first and second order conditions for a maximum are

$$
\begin{gathered}
\Gamma_{z}(z, y, \eta, B)-P_{z}(z)=0 \\
\Gamma_{z z^{\prime}}-P_{z z^{\prime}} \text { is negative definite. }
\end{gathered}
$$

Throughout, I follow the classical hedonic literature and assume the regular case in which the second order conditions hold as strict inequalities, $\Gamma_{z \eta^{\prime}}$ is positive definite, and $P_{z} U_{c \varepsilon^{\prime}}+U_{z \varepsilon^{\prime}}$ is positive definite. These conditions guarantee positive sorting on unobservables in the sense that in equilibrium $\frac{\partial \eta}{\partial z}>0$ and $\frac{\partial \varepsilon}{d z}>0$. Firms are

\footnotetext{
16 For expositional convenience, I restrict the analysis to economies in which the equilibrium price function is smooth. Similar analyses can be done for economies in which the equilibrium price function is not smooth. For an example of an economy with smooth technologies and absolutely continuous distributions of consumer heterogeneity in which the equilibrium price function is piecewise twice continuously differentiable, see Nesheim (2002).
} 
heterogeneous. Tinbergen anticipated modern developments on sorting in the labor market. $^{17}$

Heterogeneous workers differ in their preference attributes vectors $x$ and $\varepsilon$. Heterogeneous firms differ in their productivity vectors $y$ and $\eta$. Let the densities of $x$ and $\varepsilon$ be $f_{x}$ and $f_{\varepsilon}$ and let $x$ be independent of $\varepsilon . x$ and $\varepsilon$ have supports $\mathcal{X}$ and $\mathcal{E}$ respectively. The densities of $y$ and $\eta$ are $f_{y}$ and $f_{\eta}, y$ is assumed independent of $\eta$ and $y$ and $\eta$ have supports $\mathcal{Y}$ and $\mathcal{H}$ respectively. Assume that $x, \varepsilon, y$, and $\eta$ are absolutely continuous random variables. In this paper, we focus on the case in which $\operatorname{dim}(\varepsilon)=\operatorname{dim}(\eta)=\operatorname{dim}(z)$, which was also invoked by Tinbergen (1956). For this case, there is no bunching in equilibrium. That is, in equilibrium, every bundle of characteristics has population measure zero of demanders or suppliers. This is also the classical case analyzed in Rosen (1974) and the subsequent literature. For an analysis of equilibria with bunching, see Heckman et al. (2010).

Given the previous assumptions, a local implicit function theorem applies and one can invert the first order conditions (FOC) (1) and (3) to obtain $\varepsilon$ and $\eta$ as functions of $z$ and $x$ and $y$, respectively. Inverting the FOC (1) for the worker, one obtains

$$
\varepsilon=\varepsilon\left(z, P_{z}, P(z), x, A\right) .
$$

Similarly, inverting the FOC (3) for the firm, one obtains

$$
\eta=\eta\left(z, P_{z}, y, B\right) \text {. }
$$

Using these relationships, use $f_{x}$ and $f_{\varepsilon}$ to find the density of $z$ supplied given $P(z)$, and use $f_{y}$ and $f_{\eta}$ to find the density of $z$ demanded given $P(z)$.

The Supply Density is:

$$
\int_{\mathcal{X}} f_{\varepsilon}\left(\varepsilon\left(z, P_{z}, P(z), x, A\right)\right) \operatorname{det}\left[\frac{d \varepsilon\left(z, P_{z}, P(z), x, A\right)}{d z}\right] f_{x}(x) d x,
$$

where the term in square brackets is the Jacobian matrix with respect to vector $z$ (i.e., its effect on all arguments of $\varepsilon$ that depend on $z$ ). This is the density of the amenity supplied as a function of the price function, preference parameters $A$, and the densities of $x$ and $\varepsilon$.

The Demand Density is:

$$
\int_{\mathcal{Y}} f_{\eta}\left(\eta\left(z, P_{z}, y, B\right)\right) \operatorname{det}\left[\frac{d \eta\left(z, P_{z}, y, B\right)}{d z}\right] f_{y}(y) d y .
$$

Again, the term in square brackets is the Jacobian matrix with respect to vector $z$. This is the density of demand for a given price function, vector of technology parameters $B$, and pair of densities of $y$ and $\eta$. From the second order conditions (2) and (4), respectively, the Jacobian terms are both positive.

${ }^{17}$ See, e.g., Lindenlaub (2017). 
It was Tinbergen's great insight that equilibrium in hedonic markets requires that supply and demand be equated at each point of the support of $z$. Equilibrium prices $P(z)$ must satisfy the following second order partial differential equation

$$
\begin{aligned}
& \int_{\mathcal{X}} f_{\varepsilon}\left(\varepsilon\left(z, P_{z}, P(z), x, A\right)\right) \operatorname{det}\left[\frac{d \varepsilon\left(z, P_{z}, P(z), x, A\right)}{d z}\right] f_{x}(x) d x \\
= & \int_{\mathcal{Y}} f_{\eta}\left(\eta\left(z, P_{z}, y, B\right)\right) \operatorname{det}\left[\frac{d \eta\left(z, P_{z}, y, B\right)}{d z}\right] f_{y}(y) d y .
\end{aligned}
$$

The solution depends on $U$, the utility function of the workers $\Gamma$, the technology of firms, and the pairs of density functions $\left(f_{x}, f_{\varepsilon}\right)$ and $\left(f_{y}, f_{\eta}\right)$, characterizing the population distributions of workers and firms respectively. Additionally, workers and firms must receive wages and profits above reservation levels in order to participate in the market. This generates the boundary conditions that determine the solution of the partial differential equation. This entry condition also plays a role in the identification of the model (see Ekeland et al. 2004).

When $z$ is scalar and utility is quasi-linear so that $U(c, z, x, \varepsilon, A)=c-V(z, x, \varepsilon, A)$, $\frac{d \varepsilon}{d z}=\frac{P_{z z}-V_{z z}}{V_{z \varepsilon}}$ and $\frac{d \eta}{d z}=\frac{P_{z z}-\Gamma_{z z}}{\Gamma_{z \eta}}$. Since $V_{z \varepsilon}<0$ and $\Gamma_{z \eta}>0$, one can substitute these expressions into (5) to obtain an explicit expression for $P_{z z}$, the second derivative of the pricing functional:

$$
P_{z z}=\frac{\int_{\mathcal{X}} f_{\varepsilon} f_{x}\left(\frac{V_{z z}}{-V_{z \varepsilon}}\right) d x+\int_{\mathcal{Y}} f_{\eta} f_{y}\left(\frac{\Gamma_{z z}}{\Gamma_{z \eta}}\right) d y}{\int_{\mathcal{Y}} \frac{f_{\eta} f_{y}}{\Gamma_{z \eta}} d y+\int_{\mathcal{X}} \frac{f_{\varepsilon} f_{x}}{-V_{z \varepsilon}} d x}
$$

where the arguments of the functions have been suppressed for ease of exposition. In equilibrium, the curvature of the pricing function is a weighted average of the average curvature of the workers' utility and the average curvature of the firms' technology. The weights at any particular point in $z$ space depend on the ratio of the densities of worker and firm heterogeneity. Hedonic equilibrium is illustrated in Fig. 1.

The figure shows the optimal job sorting choices of 3 firm-worker pairs. The solid line depicts the equilibrium price function. The dotted lines depict firm output as a function of job type for three different firms. ${ }^{18}$ Each firm chooses the job type $z$ where the output function is tangent to the price function. The dashed lines depict worker disutility as a function of $z$ for three different workers. ${ }^{19}$ Each worker chooses the job type where disutility is tangent to the price function. Each worker matches with a firm so that the worker disutility function is tangent to the output

\footnotetext{
18 For each firm, this output function has been shifted vertically by subtracting off each firm's equilibrium profits so that all three plots fit in the same figure.

19 Each worker's disutility curve has been shifted vertically by subtracting off equilibrium utility so that all three plots fit in the same figure.
} 


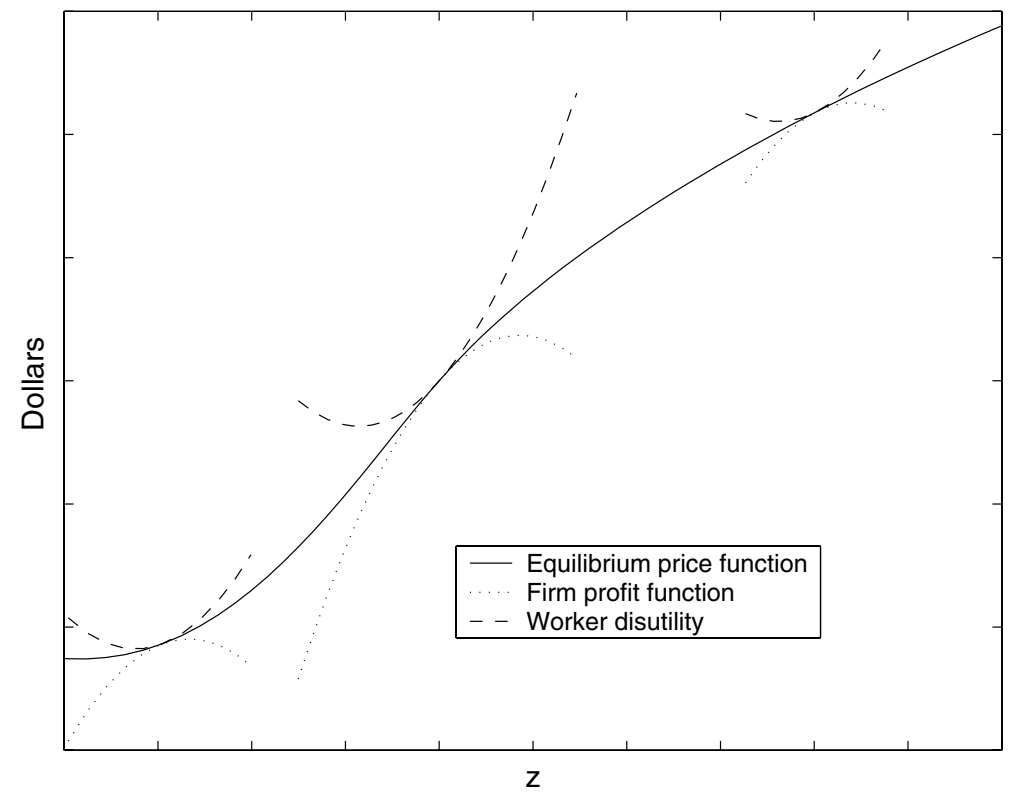

Fig. 1 Optimal job choice for three worker-firm pairs Source: Ekeland et al. (2004)

function of his matched firm. In each case the curvature of firm output is less than the curvature of the price function which is less than the curvature of worker disutility. The curvature of the pricing function is a weighted average of the curvature of the firm profit function and the curvature of worker disutility. If this were not the case, then the firms and workers would not both be choosing optimal job types.

Tinbergen (1956) pioneered the analysis of nonlinear pricing, which became a hot topic in the 1970s. ${ }^{20}$ The later literature featured nonlinear pricing as a form of price discrimination. Tinbergen's analysis applied to perfectly competitive markets. He extended manpower training models by considering that the "skill requirements" of a firm are not fixed solely by technological criteria, but also respond to aggregate skill endowments. Thus, the skill content of tasks is endogenous, as modeled in later work by Acemoglu and Autor (2011).

As discussed by Tinbergen (1956) and Rosen (1974), in the special cases where all firms are alike or all consumers are alike, the hedonic pricing function corresponds, respectively, to the firm profit or worker disutility functions. Otherwise, the curvature of the hedonic function differs from the curvature of technology or preference functions. This point is still not appreciated in much of the applied hedonic literature. ${ }^{21}$ These differences in curvature are a fundamental feature of equilibrium and provide a basis for the econometric identification results (see Ekeland et al. 2004).

\footnotetext{
${ }^{20}$ See, e.g., Armstrong (2016).

${ }^{21}$ See, e.g., Ashenfelter and Greenstone (2004).
} 


\subsection{Tinbergen's Specific Version of the Hedonic Model}

Tinbergen specifically analyzed a linear-quadratic model with normal heterogeneity, which produces a closed form expression for the hedonic pricing function. This is the model that justifies widely-used empirical approximations as exact descriptions. It is still in wide use because it is so mathematically tractable.

Assume that preferences are quadratic in $z$ and linear in $c$, unearned income $R=0$, and that individual heterogeneity $(x, \varepsilon)$ only affects utility through the single index $\theta=\mu_{\theta}(x)+\varepsilon$ where $\operatorname{dim}(\theta)=\operatorname{dim}(z){ }^{22}$ Workers maximize

$$
U(c, z, \theta, A)=P(z)+\theta^{\prime} z-\frac{1}{2} z^{\prime} A z .
$$

The conditions determining a worker's maximum are ${ }^{23}$

$$
P_{z}+\theta-A z=0
$$

where $P_{z z^{\prime}}-A$ is negative definite. On the firm side, assume that the production function is quadratic in $z$ and that firm heterogeneity only affects profits through the single index $v=\mu_{v}(y)+\eta$ where $\operatorname{dim}(v)=\operatorname{dim}(z)$. Profits are

$$
\Pi(z, v, B, P(z))=v^{\prime} z-\frac{1}{2} z^{\prime} B z-P(z)
$$

and the conditions determining a firm's optimum are

$$
v-B z-P_{z}=0
$$

where $-\left(B+P_{z z^{\prime}}\right)$ is negative definite. The distributions of $\theta$ and $v$ in the population are normal. The distribution of $\theta$ is $\theta \sim N\left(\mu_{\theta}, \Sigma_{\theta}\right)$, and the distribution of $v$ is $\nu \sim N\left(\mu_{v}, \Sigma_{v}\right)$.

An arbitrary price function induces a density of demand and a density of supply at every location $z$. The equilibrium price function can be found by equating these densities at every point $z$ and thereby solving the differential equation (5). However, in the linear-quadratic-normal case one can correctly guess that the price function that solves (5) is quadratic in $z$

$$
P(z)=\pi_{0}+\pi_{1}^{\prime} z+\frac{1}{2} z^{\prime} \pi_{2} z
$$

and then find the coefficients $\left(\pi_{0}, \pi_{1}, \pi_{2}\right)$ that satisfy the equilibrium equation. Since the price function is quadratic, the first order condition for a worker is

$$
\pi_{1}+\pi_{2} z+\theta-A z=0 .
$$

\footnotetext{
22 The model in this example was first analyzed by Tinbergen (1956) and has been used by Epple (1987), Tauchen and Witte (2001) and Lindenlaub (2017).

23 Tinbergen (1956) used the language of a "tension" between the attributes and attribute requirements. In Tinbergen (1977), he correctly notes that this is not an essential feature of his approach. "Tension" was a residual from his reliance on conventions from the manpower planning literature that conceptualized skill requirements of jobs as being solely technologically determined.
} 
For a firm, it is

$$
v-B z-\pi_{1}-\pi_{2} z=0 .
$$

The second order conditions require that both $A-\pi_{2}$ and $B+\pi_{2}$ are positive definite. Thus, we may solve for $z$ from (7) to obtain

$$
z=\left(A-\pi_{2}\right)^{-1}\left(\theta+\pi_{1}\right)
$$

and from (8) to obtain

$$
z=\left(B+\pi_{2}\right)^{-1}\left(v-\pi_{1}\right) .
$$

These equations define mappings from workers $\theta$ and firms $v$ to job types $z$. These mappings determine the density of supply and demand at every bundle of characteristics that appears in the market or attributes and the types of workers and firms at every location. Equilibrium is characterized by a vector $\pi_{1}$ and a matrix $\pi_{2}$ that equate demand and supply at all $z$. However, since both $\theta$ and $v$ are normally distributed, this only requires equating the mean and variance of supply and demand.

The mean supply $E^{S}(z)$ is obtained from (9):

$$
\text { (Average Supply) } E^{S}(z)=\left(A-\pi_{2}\right)^{-1} E\left(\theta+\pi_{1}\right) .
$$

The mean demand is obtained from (10):

$$
\text { (Average Demand) } E^{D}(z)=\left(B+\pi_{2}\right)^{-1} E\left(v-\pi_{1}\right) .
$$

Since $\mu_{\theta}=E(\theta)$ and $\mu_{v}=E(v)$, the condition $E^{S}(z)=E^{D}(z)$ implies that

$$
\text { (Equality of means) }\left(A-\pi_{2}\right)^{-1}\left(\mu_{\theta}+\pi_{1}\right)=\left(B+\pi_{2}\right)^{-1}\left(\mu_{v}-\pi_{1}\right) .
$$

Rearranging terms, we obtain an explicit expression for $\pi_{1}$ in terms of $A, B, \mu_{\theta}, \mu_{v}$ and $\pi_{2}$ :

$$
\pi_{1}=\left[\left(A-\pi_{2}\right)^{-1}+\left(B+\pi_{2}\right)^{-1}\right]^{-1}\left[-\left(A-\pi_{2}\right)^{-1} \mu_{\theta}+\left(B+\pi_{2}\right)^{-1} \mu_{\nu}\right] .
$$

To determine $\pi_{2}$, compute the variances of supply and demand from (9) and (10) respectively to obtain:

$$
\begin{aligned}
& \Sigma_{z}^{S}=\left(A-\pi_{2}\right)^{-1} \Sigma_{\theta}\left[\left(A-\pi_{2}\right)^{-1}\right]^{\prime} \\
& \Sigma_{z}^{D}=\left(B+\pi_{2}\right)^{-1} \Sigma_{\nu}\left[\left(B+\pi_{2}\right)^{-1}\right]^{\prime}
\end{aligned}
$$

where $\Sigma_{z}^{S}$ is the variance of supply and $\Sigma_{z}^{D}$ is the variance of demand. From equality of variances of the demand and supply distributions we obtain an implicit equation for $\pi_{2}$ :

(Equality of variances) $\left(A-\pi_{2}\right)^{-1} \Sigma_{\theta}\left[\left(A-\pi_{2}\right)^{-1}\right]^{\prime}=\left(B+\pi_{2}\right)^{-1} \Sigma_{\nu}\left[\left(B+\pi_{2}\right)^{-1}\right]^{\prime}$. 
One can pin down initial conditions using the restrictions that $U \geq \bar{U}$, a reservation value, and profits are positive $(\Pi \geq 0)$. After taking into account the equilibrium relationship between $v$ and $z$, equilibrium profits as a function of $z$ are $\frac{1}{2} z^{\prime}\left(B+\pi_{2}\right) z-\pi_{0}$. Since $\left(B+\pi_{2}\right)$ is positive definite by the second order conditions and we have to allow for the possibility that $z=0$, nonnegativity of profits implies $-\pi_{0} \geq 0$. Setting reservation utility equal to zero, a similar argument on the worker side implies $\pi_{0} \geq 0$. Hence $\pi_{0}=0$.

Once one has have solved for $\pi_{1}$ and $\pi_{2}$, (9) and (10) also define the equilibrium matching function linking the characteristics of suppliers $(\theta)$ to those of demanders (v). Substituting out for $z$, this function is

$$
\left(A-\pi_{2}\right)^{-1}\left(\theta+\pi_{1}\right)=\left(B+\pi_{2}\right)^{-1}\left(v-\pi_{1}\right)
$$

so the equilibrium relationship between $\theta$ and $v$ is

$$
\theta=\left(A-\pi_{2}\right)\left(B+\pi_{2}\right)^{-1}\left(\nu-\pi_{1}\right)-\pi_{1} .
$$

Because of sorting, equilibrium worker and firm characteristics are related.

In the special case where $\Sigma_{\theta}, \Sigma_{v}, A$, and $B$ are diagonal, $\pi_{2}$ is diagonal. Effectively, this is a scalar case where each attribute is priced separately. In the scalar case, equality of variances implies that $\left(A-\pi_{2}\right)^{2} \Sigma_{v}=\left(B+\pi_{2}\right)^{2} \Sigma_{\theta}$. The second order conditions imply that $A-\pi_{2}>0$ and $B+\pi_{2}>0$. Defining $\sigma_{\theta}=\left(\Sigma_{\theta}\right)^{\frac{1}{2}}$ and $\sigma_{v}=\left(\Sigma_{v}\right)^{\frac{1}{2}}$, this implies that ${ }^{24}$

$$
\begin{aligned}
& \pi_{2}=\frac{A \sigma_{v}-B \sigma_{\theta}}{\sigma_{\theta}+\sigma_{v}} . \\
& \pi_{1}=\frac{-\mu_{\theta} \sigma_{v}+\mu_{v} \sigma_{\theta}}{\sigma_{\theta}+\sigma_{v}} .
\end{aligned}
$$

$\pi_{2}$, the curvature of the price function, is a weighted average of the curvatures of workers' and firms' preference and technology functions. $\pi_{1}$ is a weighted average of the means of worker and firm distributions of heterogeneity. In both expressions, the weights depend on the relative variances of worker and firm heterogeneity. If workers are much more heterogeneous than firms $\sigma_{\theta}>>\sigma_{\nu}, \pi_{2}$ will approximately equal $B$, the curvature of firms' technology. If $\sigma_{\theta}=\sigma_{\nu}$ and $A=B, \pi_{2}=0$ is a solution and the equilibrium price function is linear in $z$. If $\sigma_{\theta}=\sigma_{v}$, but $A \neq B$, then $\pi_{2}=\frac{A-B}{2}$. In the polar cases when $\sigma_{\theta}=0$ or $\sigma_{v}=0$, there is effectively only one type of consumer or one type of firm respectively. If $\sigma_{\theta}=0$ and $\sigma_{v}>0$, then $\pi_{2}=A$ and $\pi_{1}=-\mu_{\theta}$. In this case, prices reveal the parameters of consumer preferences. If $\sigma_{v}=0$ and $\sigma_{\theta}>0, \pi_{2}=B$ and $\pi_{1}=\mu_{v}$. These two polar cases are discussed in Tinbergen (1956) and Rosen (1974) and are the ones that dominate discussions in the empirical literature on hedonic models. Only in these two polar cases do prices directly reveal consumer preferences or firm productivities, respectively. Similar

${ }^{24}$ The other root of the equation violates second order conditions. 
results hold when $z, \theta$, and $v$ are vectors. As previously noted, much of the applied literature still ignores these fundamental properties of hedonic equilibria.

\section{Tinbergen's Research in Modern Perspective}

Tinbergen's research on earnings inequality has many modern elements. He brought both demand and supply considerations to the study of the pricing of skills. He recognized the multiplicity of market-relevant skills, the heterogeneity of the skills within a single skill type (e.g., education, personality), and the nonlinearity of prices as functions of skills, even in competitive markets. He also recognized that labor markets sort heterogeneous workers and firms and developed models that characterize the pricing of skill vectors that arise from the sorting of skills in markets. He accounted for technological change in shifting the demand for skills and reallocating workers across tasks. Equating firms to tasks, he modeled how the skill content of tasks would change in response to shifts in final product demand, advances in technology, and endowments of the economy.

A major weakness of his approach was that he did not model the dynamics of skill formation. ${ }^{25}$ The profession has advanced greatly on this topic and Tinbergen did not live to see this work. ${ }^{26}$

The recent empirical literature uses dynamic recursive methods which challenge the standards of simplicity and tractability emphasized by Tinbergen in his empirical work. The long-lived nature of human capital investments induces aggregate cycles well outside the domain of any of Tinbergen's models. ${ }^{27}$

Tinbergen (1975) also did not have access to a generation of subsequent research that refined the measurement of noncognitive skills and showed how they can be fostered. ${ }^{28}$ Psychological "traits" like IQ and conscientiousness that he took as genetically-determined endowments are malleable and therefore, not a proper basis for lump sum taxation. However, the recent literature reinforces Tinbergen's fundamental point that income and earnings equalization can be made at multiple margins.

By his own admission, Tinbergen did not look at all determinants of income inequality, which still remains a challenging problem. Capital was more or less ignored and the welfare state was not comprehensively analyzed, although he allowed for disincentive effects of taxes and transfers. He did not aim for an exhaustive study of income inequality, which still remains a challenging problem. He focused on the main source of inequality in modern economies_-labor market earnings.

Tinbergen's framework endures even if important details of it needs revision. His emphasis on understanding the mechanisms producing inequality serves as a beacon for rigorous empirical research, which requires much more than having "good instruments," or "big data" to understand the origins of inequality and effective

\footnotetext{
25 He briefly discusses this in Tinbergen (1977).

26 See, e.g., Heckman et al. (1998), Keane and Wolpin (1997) and Johnson and Keane (2013).

27 See Heckman et al. (1998).

28 See, e.g., the survey in Almlund et al. (2011) and Heckman and Mosso (2014).
} 
approaches to alleviating it. He set and continues to set a high standard for investigating inequality in earnings.

\section{Conclusion}

Tinbergen made fundamental contributions. He invented the modern theory of hedonics, which has applications well beyond the labor market. His emphasis on using economics to understand outcomes in the labor market and to devise effective policies provides an inspiring example relevant for today.

Why did his pioneering research not have a greater contemporary impact on research on earnings and inequality in earnings? Several factors were in play. First, the work was mathematically sophisticated for its day. The hedonic model stretched the technical skills of most contemporary economists. Second, applying micro theory to the analysis of the labor market was unusual in an era dominated by Keynesian demand management analyses. Third, Tinbergen viewed his research as an input to designing effective planning policies. His 1975 book appeared in an era when human capital theory was beginning to sweep the profession. Planning was anathema to the leading scholars of human capital. Their analyses stopped with analyses of labor market phenomena and not abstract notions like optimal social welfare. In his day, the reception to his work was guarded. Tinbergen was caught between a Keynesian devil and a positivist deep blue sea and as a result, key insights of his work were overlooked. ${ }^{29}$

Open Access This article is distributed under the terms of the Creative Commons Attribution 4.0 International License (http://creativecommons.org/licenses/by/4.0/), which permits unrestricted use, distribution, and reproduction in any medium, provided you give appropriate credit to the original author(s) and the source, provide a link to the Creative Commons license, and indicate if changes were made.

\section{References}

Acemoglu, D., \& Autor, D. H. (2011). Skills, tasks and technologies: Implications for employment and earnings. In O. C. Ashenfelter \& D. Card (Eds.), Handbook of labor economics (Vol. 4B, pp. 10431171). Amsterdam: Elsevier.

Almlund, M., Duckworth, A. I., Heckman, J. J., \& Kautz, T. (2011). Personality psychology and economics. In E. A. Hanushek, S. Machin, \& L. Wößmann (Eds.), Handbook of the economics of education (Vol. 4, pp. 1-181). Amsterdam: Elsevier B.V.

Armstrong, M. (2016). Nonlinear pricing. Annual Review of Economics, 8, 583-614.

Ashenfelter, O., \& Greenstone, M. (2004). Using mandated speed limits to measure the value of a statistical life. Journal of Political Economy, 112(S1), S226-S267.

Atkinson, A. B., \& Bourguignon, F. (2000). Introduction: Income distribution and economics. In A. B. Atkinson \& F. Bourguignon (Eds.), Handbook of income distribution (Vol. 1, pp. 1-58). Amsterdam: Elsevier.

Autor, D. H., \& Dorn, D. (2013). The growth of low skill service jobs and the polarization of the US labor market. American Economic Review, 103(5), 1553-1597.

29 The innovative work of Bowles and Gintis (1976) suffered a similar fate in mainstream economics. 
Beaudry, P., Green, D. A., \& Sand, B. M. (2016). The great reversal in the demand for skill and cognitive tasks. Journal of Labor Economics, 34(S1), Part 2, S199-S247.

Becker, G. S. (1964). Human capital: A theoretical and empirical analysis, with special reference to education (1st ed.). Chicago: University of Chicago Press for the National Bureau of Economic Research.

Bowles, S. (1970). Aggregation of labor inputs in the economics of growth and planning: Experiments with a two-level CES function. Journal of Political Economy, 78(1), 68-81.

Bowles, S., \& Gintis, H. (1976). Schooling in capitalist America: Educational reform and the contradictions of economic life. New York: Basic Books.

Court, A. T. (1939). Hedonic price indexes with automotive examples. In The dynamics of automobile demand, pp. 99-117. New York: General Motors Corporation.

Court, L. M. (1941). Entrepreneurial and consumer demand theories for commodity spectra: Part I. Econometrica, 9(2), 135-162.

Dougherty, C. R. S. (1972). Estimates of labor aggregation functions. Journal of Political Economy, 80(6), 1101-1119.

Dresch, S. P. (1975). Demography, technology, and higher education: Toward a formal model of educational adaptation. Journal of Political Economy, 83(3), 535-570.

Ekeland, I., Heckman, J. J., \& Nesheim, L. (2004). Identification and estimation of hedonic models. Journal of Political Economy, 112(S1), S60-S109.

Epple, D. (1987). Hedonic prices and implicit markets: Estimating demand and supply functions for differentiated products. Journal of Political Economy, 95(1), 59-80.

Fallon, P. R., \& Layard, P. R. G. (1975). Capital-skill complementarity, income distribution, and output accounting. Journal of Political Economy, 83(2), 279-302.

Goldin, C. D., \& Katz, L. F. (2009). The race between education and technology. Cambridge: Harvard University Press.

Haveman, R. H. (1977). Tinbergen's income distribution: Analysis and policies - A review article. Journal of Human Resources, 12(1), 103-114.

Heckman, J. J. (2014). Private notes on Gary Becker. Technical report, IZA Discussion Paper. No. 8200.

Heckman, J. J. (2008). Schools, skills, and synapses. Economic Inquiry, 46(3), 289-324.

Heckman, J. J., Humphries, J. E., \& Veramendi, G. (2018). Returns to education: The causal effects of education on earnings, health and smoking. Journal of Political Economy, 126(S1), S197-S246.

Heckman, J. J., Lochner, L. J., \& Taber, C. (1998). Explaining rising wage inequality: Explorations with a dynamic general equilibrium model of labor earnings with heterogeneous agents. Review of Economic Dynamics, 1(1), 1-58.

Heckman, J. J., Lochner, L. J., \& Todd, P. E. (2006). Earnings functions, rates of return and treatment effects: The Mincer equation and beyond. In E. A. Hanushek \& F. Welch (Eds.), Handbook of the economics of education (Vol. 1, pp. 307-458). Amsterdam: Elsevier.

Heckman, J. J., Matzkin, R. L., \& Nesheim, L. (2010). Nonparametric identification and estimation of nonadditive hedonic models. Econometrica, 78(5), 1569-1591.

Heckman, J. J., \& Mosso, S. (2014). The economics of human development and social mobility. Annual Review of Economics, 6(1), 689-733.

Johnson, M., \& Keane, M. P. (2013). A dynamic equilibrium model of the US wage structure, 19681996. Journal of Labor Economics, 31(1), 1-49.

Katz, L. F., \& Murphy, K. M. (1992). Changes in relative wages, 1963-1987: Supply and demand factors. Quarterly Journal of Economics, 107(1), 35-78.

Keane, M. P., \& Wolpin, K. I. (1997). The career decisions of young men. Journal of Political Economy, 105(3), 473-522.

Kol, J., \& de Wolff, P. (1993). Tinbergen's work: Change and continuity. In A. Knoester \& A. Wellink (Eds.), Tinbergen lectures on economic policy (pp. 27-54). Amsterdam: North-Holland.

Lamadon, T., Mogstad, M., \& Setzler, B. (2017). Earnings dynamics, mobility costs, and transmission of market-level shocks. In Society for Economic Dynamics (1483). 2017 Meeting Papers.

Lindenlaub, I., \& Postel-Vinay, F. (2017). Multidimensional sorting under random search. In 2017 Meeting Papers, no. 501. Society for Economic Dynamics.

Lindenlaub, I. (2017). Sorting multidimensional types: Theory and application. The Review of Economic Studies, 84(2), 718-789.

Mincer, J. (1974). Schooling, Experience, and Earnings. New York: Columbia University Press for National Bureau of Economic Research. 
Nesheim, L. (2002). Equilibrium sorting of heterogeneous consumers across locations: Theory and empirical implications. Ph.D. thesis, University of Chicago. Center for Microdata Methods and Practice (CEMMAP) Working Paper, No. CWP08/02.

Piketty, T. (2014). Capital in the twenty-first century (trans: Goldhammer, A.). Cambridge: The Belknap Press of Harvard University Press.

Reder, M. W. (1969). A partial survey of the theory of income size distribution. In Soltow, L. (Ed.), Six papers on the size distribution of wealth and income, pp. 205-250. NBER.

Rosen, S. (1974). Hedonic prices and implicit markets: Product differentiation in pure competition. Journal of Political Economy, 82(1), 34-55.

Spence, A. M. (1974). Market signaling: Informational transfer in hiring and related screening processes (Vol. 143). Cambridge: Harvard University Press.

Staehle, H. (1943). Ability, wages, and income. The Review of Economics and Statistics, 25(1), 77-87.

Tauchen, H., \& Witte, A. D. (2001). Estimating hedonic models: Implications of the theory. In NBER Working Paper Series, Technical Working Paper 271.

Tinbergen, J. (1954). Centralization and decentralization in economic policy. Amsterdam: North-Holland Publishing Company.

Tinbergen, J. (1956). On the theory of income distribution. Weltwirtschaftliches Archiv, 77, 155-173.

Tinbergen, J. (1975). Income distribution: Analysis and policies. New York: North-Holland Publishing Company.

Tinbergen, J. (1977). Income distribution: Second thoughts. De Economist, 125(3), 315-339.

Welch, F. (1969). Linear synthesis of skill distribution. Journal of Human Resources, 4(3), 311-327.

Yamaguchi, S. (2012). Tasks and heterogeneous human capital. Journal of Labor Economics, 30(1), 1-53.

Publisher's Note Springer Nature remains neutral with regard to jurisdictional claims in published maps and institutional affiliations. 